\title{
Artículos
}

\section{Espacios urbanos de frontera e integración social: un abordaje a través del espacio público}

\section{Urban border areas and social integration: An approach through the public space}

\author{
Julieta Dalla Torre* \\ Matías Ghilardi**
}

\section{Resumen}

Actualmente las ciudades atraviesan intensos procesos de transformación asociados a la segregación social y la fragmentación

* Instituto Multidisciplinario de Estudios Sociales Contemporáneos (nodo de la Unidad Ejecutora en Red Instituto de Estudios Históricos, Económicos, Sociales e Internacionales), Conicet. Dirección: IDEHESI/Conicet, $5^{\circ}$ piso, Facultad de Filosofía y Letras, Universidad Nacional de Cuyo, 5500, Ciudad de Mendoza, Argentina. Correo: julietadallatorre@gmail.com ORCID: https://orcid.org/0000-00021355-0445

** Instituto Multidisciplinario de Estudios Sociales Contemporáneos (nodo de la Unidad Ejecutora en Red Instituto de Estudios Históricos, Económicos, Sociales e Internacionales), Conicet. Argentina. Correo: mghilardi@ffyl.uncu.edu.ar ORCID: https://orcid.org/0000-0003-0390-3961

Nota de los autores: El presente artículo es fruto de un trabajo de investigación financiado por Conicet, Argentina. Una versión inicial del mismo formó parte del III Seminario Bordes, Límites, Frentes e Interfaces: Múltiples escalas en la construcción de las fronteras argentinas, que fue organizado en 2018 por el Grupo de Estudio sobre Fronteras y Regiones (GEFRE), Instituto de Geografía, Facultad de Filosofía y Letras, Universidad de Buenos Aires, y el Instituto Multidisciplinario de Estudios Sociales Contemporáneos (IMESC), nodo de la Unidad Ejecutora en Red Instituto de Estudios Históricos, Económicos, Sociales e Internacionales (IDEHESI), Conicet. 
espacial. El resultado es el poco contacto entre clases y la débil construcción colectiva de los espacios públicos, cada vez más frágiles. Este artículo indaga un proyecto de intervención en el espacio urbano en la Ciudad de Mendoza, Argentina. Se considera que el mismo constituye un espacio de frontera que tiende a integrar territorios en desuso y a sus agentes intervinientes más allá de los objetivos explícitos (relacionados con el diseño urbano e infraestructura) que presentaba el proyecto. El estudio se realizó a partir del análisis de documentos oficiales, observaciones y entrevistas.

Palabras clave: ciudades; espacio público; políticas públicas; integración social; fronteras.

\section{Abstract}

Cities are currently undergoing intense processes of transformation associated with social segregation and spatial fragmentation. The result is little contact between classes and the weak collective construction of increasingly fragile public spaces. The article investigates a project of intervention in urban space in the City of Mendoza, Argentina. It is considered that it constitutes a frontier space that tends to integrate disused territories and their intervening agents beyond the explicit objectives (related to urban design and infrastructure) presented by the project. The study was carried out on the basis of the analysis of official documents, observations and interviews.

Keywords: cities; public space; public policies; social integration; borders.

\section{Introducción}

El capitalismo globalizado y su modelo neoliberal de construcción de ciudades se caracteriza por la generación de aislamiento entre los diversos grupos sociales y la consiguiente segregación de parte de éstos. Así, actualmente las ciudades intermedias, al igual que las grandes aglomeraciones urbanas, atraviesan intensos procesos de transformación asociados a la fragmentación espacial. El resultado es el poco contacto entre las clases y la débil construcción colectiva 
de los espacios públicos, cada vez más frágiles. Frente a estas situaciones, los gobiernos desarrollan políticas territoriales que en sus objetivos -al menos discursivamente- buscan integración, interacción y contacto.

Esto lleva a pensar en las fronteras intraurbanas que se construyen cotidianamente en el espacio público a partir de los procesos de segregación, y de pensarlas y entenderlas como territorios importantes de encuentro y no sólo como bordes de separación; por lo tanto, como áreas de relación, posible integración y construcción colectiva. Entendemos al espacio público como aquél de construcción colectiva y fundamental para garantizar el derecho a la ciudad.

Este artículo se ubica en los análisis de la articulación entre políticas urbanas, fronteras e integración social. Particularmente se centra en la indagación de una política de intervención urbana desarrollada en la Ciudad de Mendoza, Argentina, a partir del año 2014, que significó la construcción de una zona de recreación y de recuperación del espacio público, denominada Parque Lineal Norte.

Se indaga el proceso de diseño y aplicación de este ejemplo de intervención urbana en el marco de las políticas territoriales desarrolladas por el gobierno municipal, en vinculación con los gobiernos provincial y nacional. Las preguntas a responder plantean: ¿cuál fue el rol del Estado en la consolidación del espacio público?, ¿cuáles fueron los objetivos buscados por el gobierno con la realización de la obra?, ¿cómo se la pensó en relación con otras prácticas territoriales gubernamentales?, ¿cuál fue el lugar que se le dio a la integración urbana y al derecho a la ciudad?, ¿qué mejoras pueden identificarse en el área estudiada?

Se considera que el Parque Lineal Norte, que constituye un espacio de frontera interno en la Ciudad de Mendoza, puede pensarse a partir de la política urbana como un espacio de relación e integración social.

El trabajo combina el análisis de fuentes secundarias oficiales a escalas nacional, provincial y municipal, así como la observación directa y entrevistas individuales en el campo.

El artículo se organiza en seis apartados. El primero presenta el caso de intervención urbana estudiado. El segundo caracteriza a la Ciudad de Mendoza, donde se desarrolla la política. En tercer lugar, 
se presenta un breve estado del arte con algunos de los principales antecedentes que ubican a la investigación dentro del campo de estudios del espacio público y las políticas públicas territoriales a nivel local, nacional e internacional. A continuación, en el cuarto, se analizan dichas políticas, que contextualizan la intervención urbana indagada, a escala municipal, provincial, nacional e internacional. En el quinto apartado se estudia la intervención desarrollada en el Parque Lineal Norte de la Ciudad de Mendoza y su vinculación con la idea de integración social. Para concluir, se incluyen las reflexiones finales y la bibliografía citada.

\section{El caso de intervención urbana: el Parque Lineal Norte en la Ciudad de Mendoza, Argentina}

El análisis realizado en este artículo se centra en un ejemplo reciente de intervención estatal urbana realizada en el centro-oeste de la Ciudad de Mendoza, Argentina; entendida como la reconversión de parte de la estructura ferroviaria existente y su transformación en el Parque Lineal Norte, también denominado Paseo o Ciclovía Nicolino Locche, en honor a un famoso boxeador local.

Este parque data del año 2014, se ubica en la Cuarta Sección de la Ciudad de Mendoza y se extiende de sur a norte por la calle Perú, desde la calle Videla Correa a avenida General Mosconi, con una extensión de $1.18 \mathrm{~km}$ y una superficie total de 2.7 hectáreas. El mismo limita al sur con el Parque Central (el segundo parque en extensión de la Ciudad de Mendoza, luego del Parque General San Martín); al norte, con el Paseo Mosconi-Houssay -ubicado en la margen sur del Zanjón de Los Ciruelos-, sirviendo este último de límite administrativo con el municipio de Las Heras; al oeste con la calle Perú y el inicio de la Sexta Sección; y al este con la Cuarta Sección.

En síntesis, se puede afirmar que el Parque Lineal Norte integra el espacio público que va desde el Parque Central al Paseo Mosconi-Houssay, y que favorece la conexión oeste-este entre las áreas residenciales de la Cuarta y la Sexta Sección de la ciudad (Mapas $1,2$ y 3$)$. 


\section{Mapa 1}

Área de estudio: principales piezas urbanas

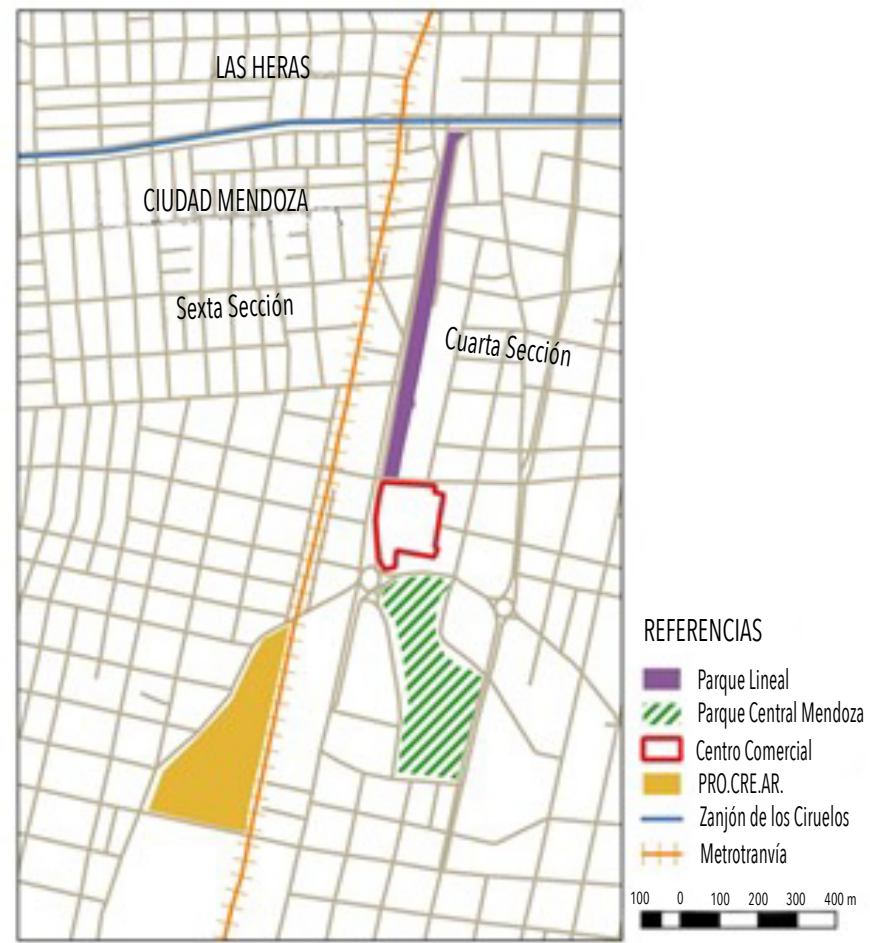

Fuente: Elaboración propia en base a fotografía aérea y cartografía oficial del Instituto Geográfico Nacional.

Antes de la construcción del Parque Lineal Norte, el área en el que fue emplazado (ubicada hacia el noroeste del Parque Central) se encontraba absolutamente aislada; el paseo de los transeúntes se realizaba en este gran parque y el resto del terreno se encontraba en desuso con falta de iluminación, señalización, pasos peatonales y demás infraestructura urbana necesaria. En el pasado toda el área constituía un gran terreno por donde pasaban las vías del ferrocarril. La misma estaba compuesta de fincas y viñas, con un único acceso por la calle Moreno. También existía allí la antigua Planta Embotelladora Villa- 
vicencio, que contaba con un grifo de acceso público desde el cual los/as vecinos/as se proveían de agua mineral para su consumo, de forma gratuita. Esta empresa privada motorizaba las actividades comerciales de la zona y daba vida a la misma hasta su traslado hacia las afueras del Área Metropolitana de Mendoza (AMM) a mediados de la década de 1990. La planta quedó en desuso y el terreno total fue sectorizado y vendido en partes.

\section{Mapa 2}

Parque Lineal Norte, Ciudad de Mendoza, Argentina

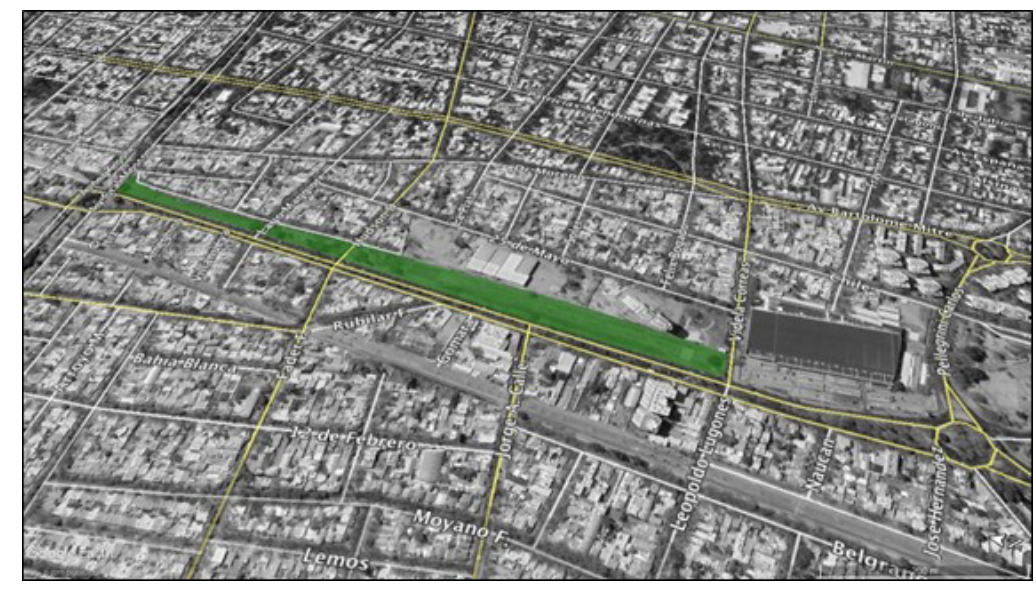

Fuente: Elaboración propia con base en datos provistos en Google Earth Pro.

Hacia los años 2000 se inició en la zona un desarrollo inmobiliario privado de gran envergadura llamado Casa Magna, que en un comienzo implicaría la construcción de cuatro torres de departamentos en una superficie total de $80000 \mathrm{~m}^{2}$ en el terreno de la antigua planta Villavicencio (Imagen 1); sin embargo, sólo se edificó la primera de las torres, que colinda al oeste con el Parque Lineal Norte (Imagen 1 y Fotografía 1). 


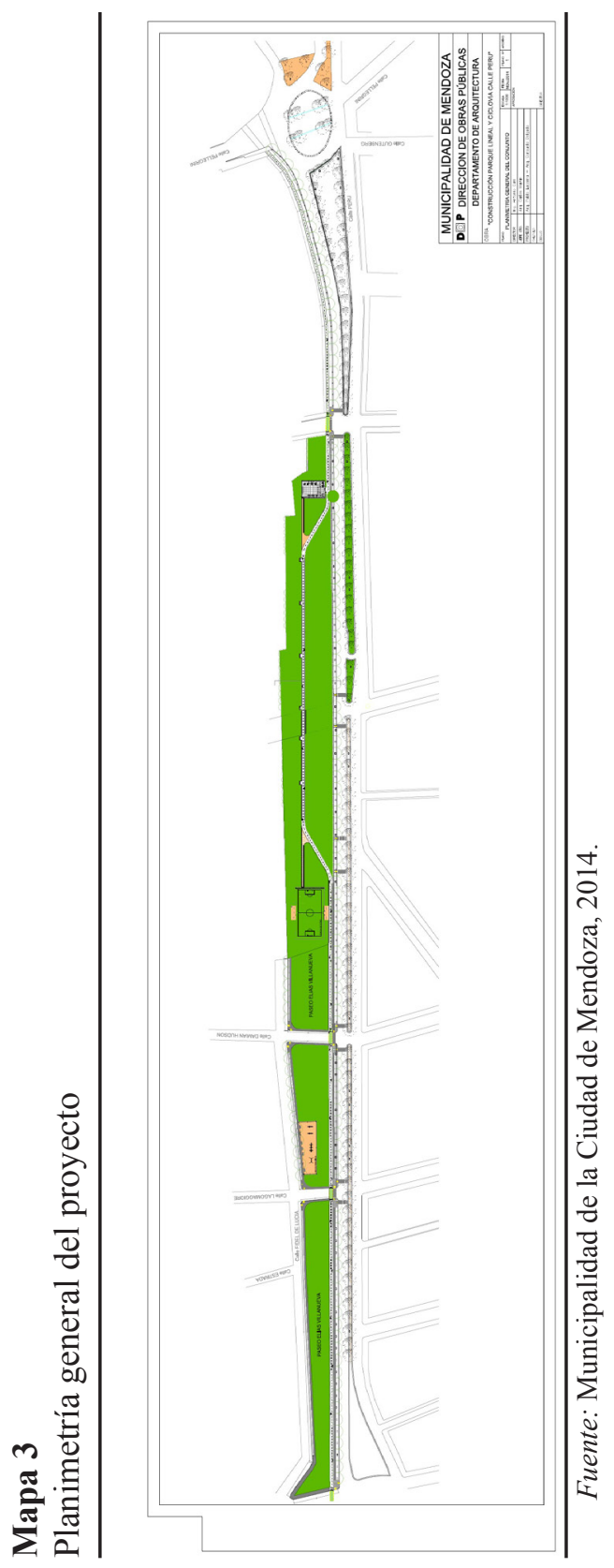




\section{Imagen 1}

Imagen publicitaria del proyecto original de Casa Magna; Ciudad de Mendoza, Argentina

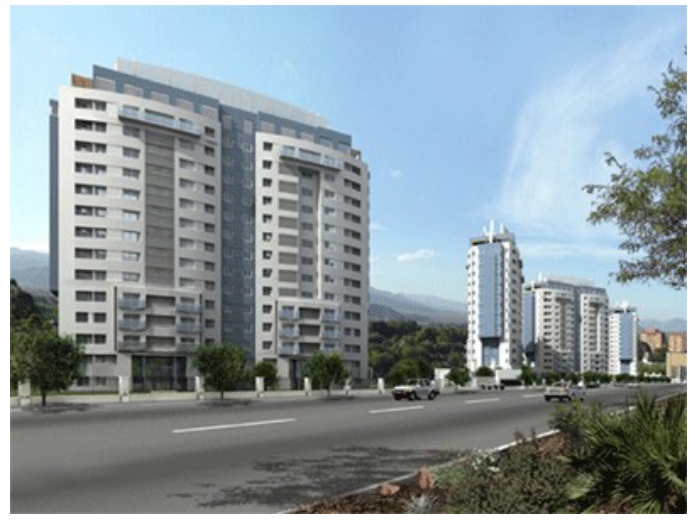

Fuente: Sitio web Construya Calidad (s/f).

\section{Fotografía 1}

Construcción del Parque Lineal Norte, Ciudad de Mendoza, Argentina

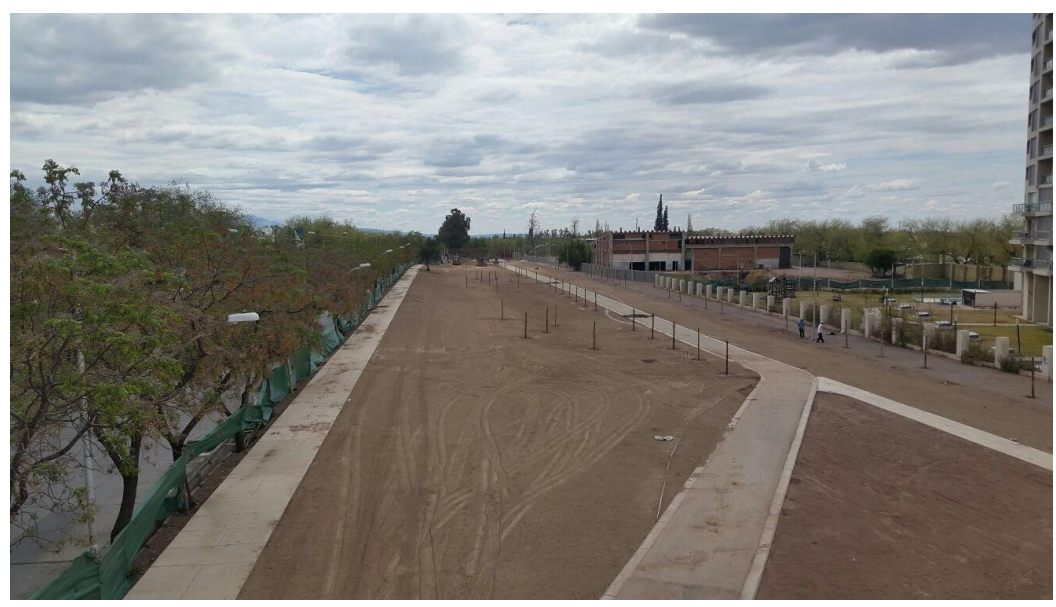

Fuente: Redacción Diario Noticias de Cuyo (s/f). 


\section{Ciudad de Mendoza, Argentina: escenario de la política urbana analizada}

La Ciudad de Mendoza es la capital de la provincia del mismo nombre y se encuentra al pie de la Cordillera de los Andes. Forma parte del Área Metropolitana de Mendoza (AMM) (Mapa 4), que constituye el cuarto aglomerado de Argentina después de Buenos Aires, Córdoba y Rosario. Según el último Censo Nacional de Población, Hogares y Vivienda, de 2010, el AMM alberga a poco más de un millón de habitantes (1086700), que representan alrededor del 62.5\% del total provincial (1738929 habitantes) (DEIE). Esta aglomeración se extiende por seis unidades territoriales denominadas departamentos, cada uno de los cuales constituye un municipio. Dos de ellos se encuentran prácticamente aglomerados en su totalidad: Ciudad de Mendoza (área urbana en la que se centra el presente trabajo y capital de la provincia) y Godoy Cruz. En cambio, los territorios municipales de Las Heras, Guaymallén, Luján de Cuyo y Maipú son abarcados, de manera parcial, por la aglomeración.

\section{Mapa 4}

Área Metropolitana de Mendoza, Argentina, 2019

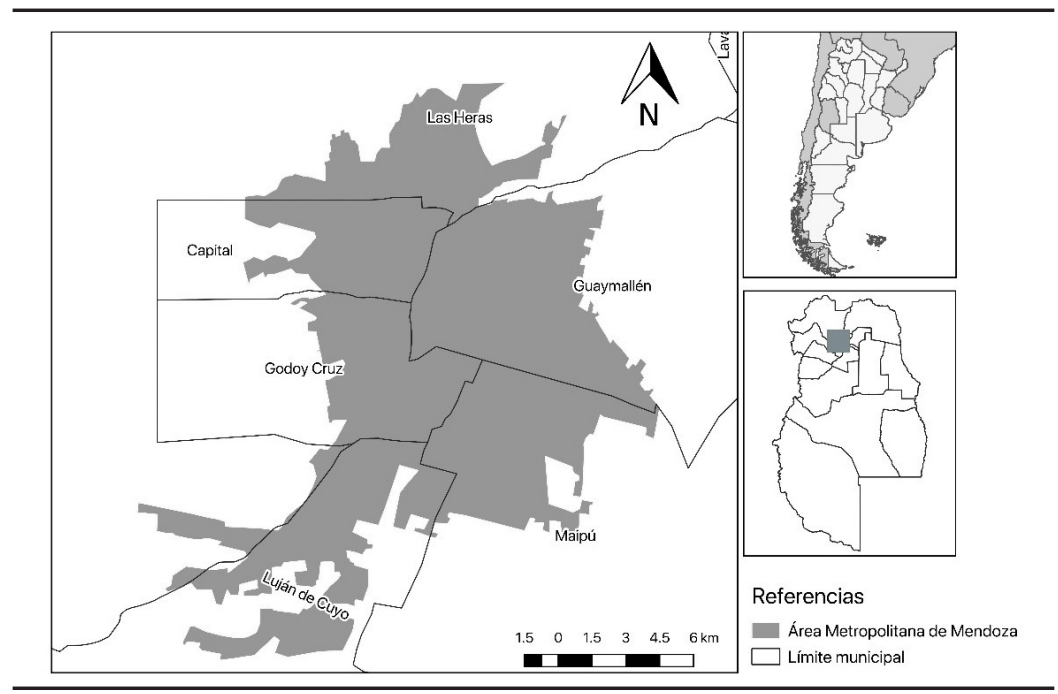

Fuente: Elaboración propia.

Estudios Demográficos y Urbanos, vol. 36, núm. 3 (108), sept.-dic., 2021, pp. 963-999 http://dx.doi.org/10.24201/edu.v36i3.1992 


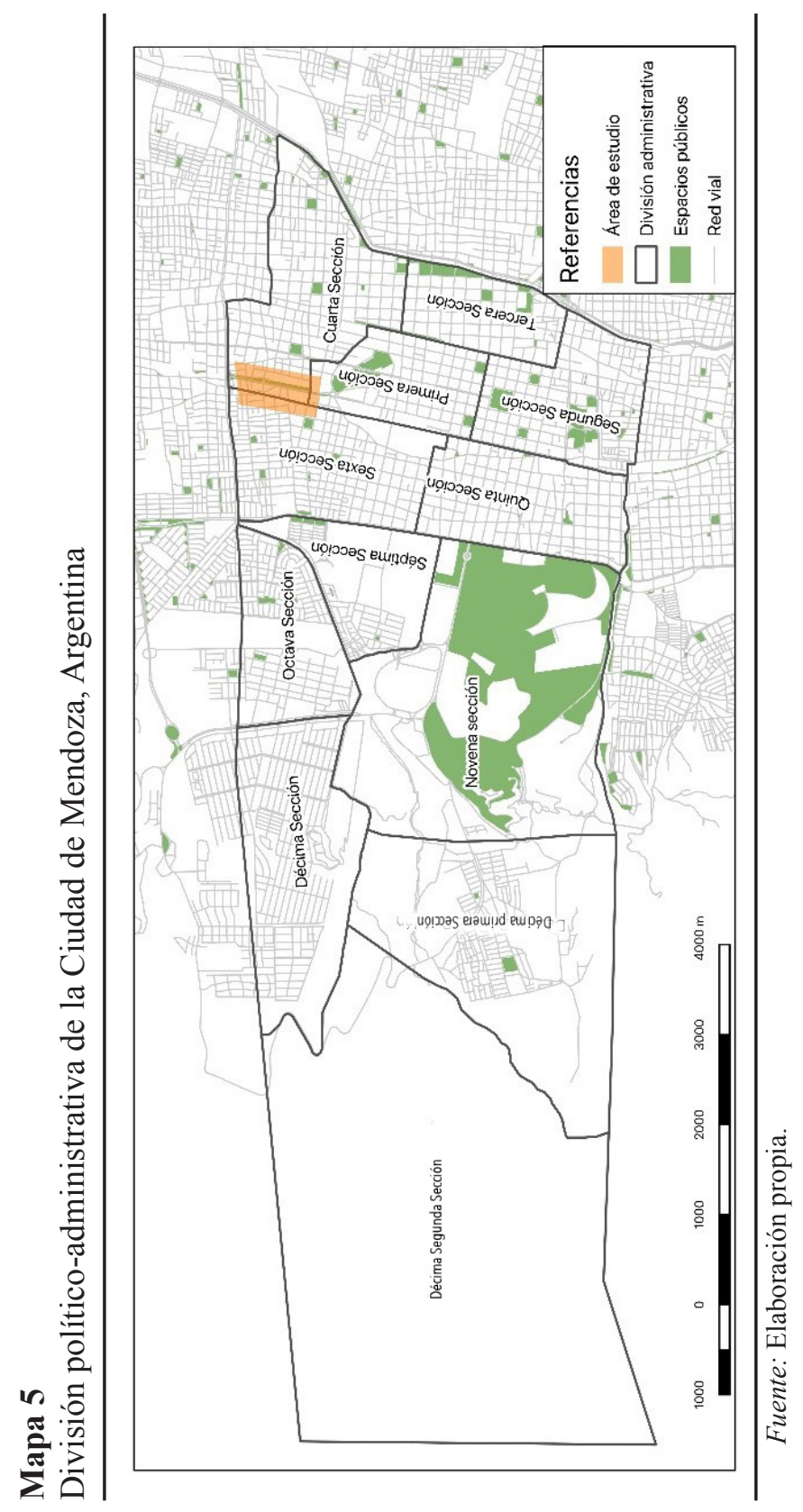


La Ciudad de Mendoza se divide en doce secciones (Mapa 5) que constituyen zonas homogéneas con características propias. Las primeras seis se ubican desde avenida Boulogne Sur Mer al este hasta el límite con el municipio de Guaymallén, con una estructura similar entre éstas; mientras que las seis secciones restantes, que se extienden desde avenida Boulogne Sur Mer hacia el oeste hasta las Sierras de Uspallata, responden a características especiales de tamaño, uso y ocupación (Municipalidad de la Ciudad de Mendoza, 2019). La Ordenanza Municipal 3505/2 agrega seis secciones nuevas hacia el oeste de avenida Boulogne Sur Mer; así se incluye el sector del piedemonte al área urbana.

La Ciudad de Mendoza tiene 115041 habitantes según el Censo 2010, y una proyección de 119450 al 2018 (INDEC). Sin embargo, su población se ve a diario significativamente aumentada por los habitantes de otros municipios que llegan por diferentes motivos (Municipalidad de la Ciudad de Mendoza, 2019). Aquí se encuentra el centro o microcentro que concentra gran parte de las actividades provinciales culturales, comerciales, bancarias y administrativas, así como el Centro Cívico que alberga al poder judicial provincial, a la sede de los tribunales federales radicados en Mendoza, a la Casa de Gobierno (sede del Poder Ejecutivo Provincial), al edificio de la Agencia de Administración Tributaria de Mendoza y a la Municipalidad.

El Área Metropolitana de Mendoza es una aglomeración que no tiene una unidad administrativa de carácter metropolitano, lo cual genera problemas de gestión y de planificación urbana. En cambio, sí cuenta con límites político-administrativos entre los seis municipios del AMM de la que forma parte, y con fronteras materiales y simbólicas que van más allá de lo administrativo, como algunos accesos, avenidas, zanjones, entre otros, que se vuelven elementos de división y separación interdepartamentales.

Tanto en la Ciudad de Mendoza como en el AMM, hacia los años noventa, y sostenidamente desde entonces, se desarrollan emprendimientos urbanos, en general privados, y otros financiados por el Estado como los barrios de vivienda social. Se comienza a configurar así un tipo de trama urbana difusa y fragmentada, con una menor disponibilidad de espacios públicos, y un trazado de nuevas calles y vías de acceso interrumpidas, con lo cual la ciudad comienza a 
fragmentarse, resultando en un conjunto de espacios segregados con cada vez menor interacción entre ellos. Muchas de estas nuevas islas residenciales se instalan en lugares carentes de servicios, infraestructura y equipamiento, o en lugares riesgosos (Marina-Berón, Padilla Rodríguez y Rapali, 2013, p. 101).

La producción del espacio urbano en la ciudad avanza hacia la edificación de torres o viviendas privadas, horizontales, cerradas y ubicadas en el centro de la aglomeración, como parte de los procesos de expansión inmobiliaria de los capitales concentrados. También, la ciudad se extiende hacia el oeste, área conocida como el piedemonte (un espacio compartido con los departamentos Godoy Cruz, Las Heras y Luján de Cuyo, y que presenta importantes niveles de fragilidad ambiental y escasez de bienes y servicios públicos).

En el piedemonte mendocino prevalecen loteos cerrados destinados a sectores medios y altos que buscan resguardar su seguridad. Pero también se desarrollan conjuntos de viviendas muy precarias a modo de asentamientos populares urbanos, donde los grupos más vulnerados en sus derechos a la ciudad -los habitantes más pobres de la urbe- construyen sus territorios con grandes limitaciones por la desposesión de suelo que padecen ante los grupos que monopolizan las rentas. Así, se ubican -esperando sea de manera temporal, provisoria- en áreas degradadas y segregadas que despiertan poco interés al mercado. Estos agentes se ubican y apropian de espacios en el sentido de "islas de precariedad", como las llama Janoschka (2002); se ven desplazados a vivir en asentamientos informales y/o barrios que los aíslan de manera gradual de la dinámica urbana de la ciudad formal.

En el piedemonte también se conjugan barrios de vivienda social financiados por el gobierno provincial y/o nacional, algunos de los cuales son producto de la relocalización de asentamientos populares antes ubicados en zonas céntricas de la ciudad con alto valor inmobiliario (Ghilardi y Dalla Torre, 2016).

Simultáneamente a las transformaciones espaciales arriba explicitadas, la Ciudad de Mendoza ha desarrollado una fuerte apuesta al turismo y, por lo tanto, concentra muchas actividades vinculadas al área de servicios: hotelería, restaurantes, transporte turístico, entre otras, en gran parte destinada al turismo extranjero con alto poder adquisitivo. 


\section{Algunas investigaciones sobre el espacio público y las transformaciones urbanas}

La revisión de antecedentes referidos al espacio público, para contextualizar la problemática, dio cuenta de la existencia de un gran número de investigaciones; por cuestión de extensión, sólo se retoman algunas referidas al espacio público de la Ciudad de Mendoza.

Desde la geografía, Rizzo $(2005 ; 2010)$ realiza un análisis de las prácticas sociales en el espacio público urbano en los últimos treinta años desde la perspectiva de Lefebvre. El espacio público es estudiado desde las prácticas espaciales de resistencia social como un espacio de interacción y participación social. Textos como los de Salomone $(2011 ; 2012)$ también plantean el espacio público como territorio de disputas. El trabajo indaga la lucha realizada en defensa de los terrenos del ferrocarril ubicados en la Ciudad de Mendoza, entendidos como parte del espacio público a defender del avance del mercado inmobiliario.

En el ámbito de la arquitectura, se encuentran las investigaciones de Raffa, quien analiza el espacio público desde una mirada histórica (2016), y también lo estudia junto al patrimonio arquitectónico mendocino (Raffa, 2017).

El espacio público también ha sido indagado en el marco de la Ley de Ordenamiento Territorial y Uso del Suelo de la Provincia de Mendoza. Investigaciones como la de Gudiño (2010) y Marina-Berón, Padilla Rodríguez y Rapali (2013) dan cuenta de los beneficios de esta nueva normativa territorial para la construcción y preservación de los espacios públicos.

Lentini, Palero y Montaña (2010) estudian la inequidad en el acceso al suelo urbano en el AMM y los procesos de segregación residencial que ello supone; el foco está puesto en las políticas habitacionales. También Lentini y Palero (2008) trabajan el derecho a la vivienda y a la ciudad en el Gran Mendoza a partir de un estudio de caso de radicación-relocalización de asentamientos informales y cuestionan la gestión de la vivienda social para los sectores de más bajos recursos en un contexto de gentrificación de la ciudad.

La línea de investigación de Roitman (2000; 2003) se centra en el estudio del AMM y sus transformaciones territoriales evidencia- 
das hacia fines del siglo XX y principios del XXI, fundamentalmente las vinculadas al surgimiento de los barrios privados y los procesos de segregación y de pérdida del espacio urbano que ellas suponen.

A nivel nacional existe una amplísima producción especializada; entre ésta, Di Virgilio y Rodríguez (2013) y Di Virgilio et al. (2011) compilan diversos análisis sobre las transformaciones urbanas en Argentina y su vínculo con las políticas públicas desarrolladas en torno al acceso al suelo urbano y la producción social del hábitat. Barreto (2010) trabaja sobre el concepto del hábitat digno con base en una indagación de los enfoques predominantes de las políticas públicas en las últimas décadas; afirma que la política debe promover la integración social a partir de los derechos humanos. También Del Río, Vértiz y Ursino (2004) analizan la acción pública en el espacio urbano.

En España son importante los estudios de Borja y Muxí (2003) y Borja (2014), en los que se indaga el espacio público, los derechos ciudadanos y el papel del Estado.

\section{Antecedentes de políticas urbanas para pensar la Ciudad de Mendoza, Argentina}

A continuación, se destacan los principales documentos vinculados a acuerdos y prácticas políticas sobre los territorios, que regulan y definen a distintas escalas a las áreas urbanas analizadas y a sus problemáticas. Es importante recuperar dichos antecedentes para pensar en el encuadre político-legal y en el contexto histórico del fenómeno estudiado, así como en los distintos niveles que lo atraviesan: supranacional, nacional, provincial y municipal.

A nivel nacional, en el año 2004 el gobierno de Néstor Kirchner puso en marcha el Plan Estratégico Territorial (PET), que puede considerarse una de las herramientas de concreción de la Política Nacional de Desarrollo y Ordenamiento Territorial (OT) de Argentina. El PET buscaba elaborar un plan federal de inversión en infraestructura y equipamiento en el territorio para "construir una Argentina integrada, equilibrada, sustentable y socialmente justa” (Ministerio de Planificación Federal, Inversión Pública y Servicios, 2008, p. 11). Este objetivo se diversificó y hoy comprende una gran cantidad de líneas 
de acción en constante actualización. Así, el PET ha tenido varias reformas a partir de las diversas experiencias en intervenciones territoriales a través de los años.

También, desde 2007 en la Secretaría de Planificación Territorial y Coordinación de Obra Pública de la nación se desarrolló el Programa Argentina Urbana, el cual tenía como objetivo fundamental profundizar en el conocimiento de las características del sistema urbano nacional, identificando los fenómenos recurrentes que requieren del accionar de gobierno para su corrección; además, generar políticas públicas desde el gobierno nacional y consensuadas por los gobiernos provinciales y locales, vinculadas al PET. Asimismo, pretendía estudiar la gran cantidad de ciudades intermedias que componen el sistema urbano nacional, poco conocidas por la centralidad de los estudios sobre las grandes ciudades.

En 2011 se publicó un segundo documento del PET, que constituyó un avance respecto del original. El mismo planteaba los lineamientos estratégicos para el desarrollo de una política de urbanización nacional. Se incluía un apartado sobre el derecho a la ciudad y sobre cómo se produce ésta (Ministerio de Planificación Federal, Inversión Pública y Servicios, 2011).

Hacia el año 2018 el Ministerio del Interior, Obras Públicas y Vivienda de la República Argentina publicó el Avance IV del PET, entendido como un instrumento de planificación para la inversión pública y privada, el desarrollo regional y la ordenación de los territorios. El documento buscó coordinar el trabajo entre los ministerios nacionales y las provincias, y explicitó la planificación territorial nacional, regional y provincial; entre esta última, la de Mendoza.

Por otro lado, como resultado de la Conferencia de las Naciones Unidas sobre la Vivienda y el Desarrollo Urbano Sostenible, Hábitat III, todas las naciones participantes, entre ellas Argentina, debieron elaborar un informe. Éste tiene por objetivo mejorar la gestión de las tierras urbanas teniendo en cuenta la expansión que presentan y así proyectar un crecimiento urbano compacto dentro de los límites de cada ciudad. Se sostiene que es necesaria la recuperación del Estado nacional en su rol de "promotor de políticas públicas orientadas hacia una configuración del territorio más equilibrado e inclusivo" (Ministerio del Interior, Obras Públicas y Vivienda, 2016, p. 7). Asi- 
mismo, el informe da cuenta de las dificultades existentes en el país en materia de regulaciones, puntualmente la falta de planes nacionales que ordenen y se articulen con las provincias y los municipios. También plantea la necesidad de mejorar la capacidad técnica para la gestión del suelo y el hábitat de los gobiernos locales.

A nivel nacional y supranacional se puede identificar la Agenda 2030 de Naciones Unidas, la cual contiene 17 objetivos de Desarrollo Sostenible con 169 metas. Uno de éstos (el 11: "Ciudades y comunidades sostenibles") se centra en las urbes: "las ciudades y los asentamientos humanos sean inclusivos, seguros, resilientes y sostenibles" (Consejo Nacional de Coordinación de Políticas Sociales, 2019). Entre sus metas están:

11.3) Aumentar la urbanización inclusiva y sostenible y la capacidad para la planificación y la gestión participativas, integradas y sostenibles de los asentamientos humanos [...].

11.7) Proporcionar acceso universal a zonas verdes y espacios públicos seguros, inclusivos y accesibles, en particular para las mujeres y los niños, las personas de edad y con discapacidad.

A escala provincial, Mendoza es pionera en la elaboración de legislación territorial. En 2009 se dictó la Ley Provincial de Ordenamiento Territorial y Usos del Suelo (Ley núm. 8051). Años más tarde, en 2018, en el marco de esta ley se definió el Plan Provincial de Ordenamiento Territorial (PPOT) (Ley núm. 8999), que constituye el primer antecedente a nivel nacional que le da marco legal al ordenamiento territorial de la provincia. El mismo engloba los procesos, lineamientos, medidas correctivas, de conservación y de desarrollo territorial que las reparticiones y organismos provinciales y los municipios tendrán que cumplir e implementar en el corto, mediano y largo plazos, para garantizar la interacción entre las distintas instituciones y los mecanismos de participación social.

En ese contexto, los 18 municipios que conforman la provincia de Mendoza deben elaborar sus propios planes de ordenamiento territorial para delinear sus políticas territoriales en función de sus particularidades. 
A inicios de 2019, la Ciudad de Mendoza finalizó su Plan Municipal de Ordenamiento Territorial (PMOT), que tiene por meta fundamental establecer objetivos de desarrollo sustentable del territorio:

Avanzar hacia un territorio departamental equilibrado, continuo y diverso, mediante la planificación de un desarrollo urbanístico socialmente equitativo y ambientalmente amigable [...] con el fin de garantizar el bien común [Municipalidad de la Ciudad de Mendoza, 2019, p. 3].

El Plan fue puesto a disposición ciudadana para su discusión en audiencia pública: "se propuso un espacio de comunicación y participación activa entre el municipio y la comunidad" (Secretaría de Planificación, Infraestructura y Ambiente, 2019, p. 2).

Asimismo, la Secretaría de Planificación, Infraestructura y Ambiente de la Ciudad de Mendoza cuenta con la Subsecretaría de Desarrollo Urbano. Entre sus principales acciones actuales está el Plan de Renovación Urbana 2016-2021, financiado en conjunto por el municipio de ciudad y por la nación, y supone la renovación de plazas, paseos, parques y otros espacios públicos, y del microcentro. También ha realizado la mejora en infraestructura de barrios vulnerables del piedemonte, y la extensión y consolidación de ciclovías que unen varios puntos de la ciudad, entre otras modificaciones.

\section{Pensar la articulación entre espacio público, fronteras e integración social}

Los territorios como construcciones sociales y, por tanto, históricas (Benedetti, 2011), constituyen la apropiación material y/o simbólica de un espacio por parte de actores sociales y suponen siempre una dominación, un control, una delimitación o el establecimiento de límites que le dan forma y lo constituyan como tal (Dalla Torre y Ghilardi, 2019). El territorio relevante para esta investigación es la ciudad, cuya construcción colectiva no significa que de ella participen todos sus agentes. En este sentido, las prácticas sociales en una urbe pueden ser favorecidas o no por el Estado y sus políticas territoriales. 
Dentro de la ciudad, el espacio público es el área de uso colectivo y, como tal, de "conflictos y equilibrios provisorios en el que las relaciones sociales desarrolladas están permanentemente en proceso de producción y coproducción" (Galarza y Corte, 2015, p. 323); es "a la vez condición y expresión de la ciudadanía, de los derechos ciudadanos [...] donde la sociedad se escenifica; [...] se construye la memoria colectiva" (Borja, 2014, pp. 111-112). Como afirman Borja y Muxí (2003, pp. 13-14), "el espacio público tiende fundamentalmente a la mezcla social, hace de su uso un derecho ciudadano de primer orden". Entonces, que el espacio público permita el encuentro social, lleva a preguntarse: ¿cómo determinadas políticas públicas habilitan la construcción de espacios públicos en la Ciudad de Mendoza?, y particularmente, ¿cómo la construcción del Parque Lineal Norte favorece la apropiación del espacio público, la integración social y el derecho a la ciudad?

El encuentro o la integración urbana se vincula con la idea del espacio público y de la convivencia que allí puede darse. Integración como "desegregación” (Ruiz-Tagle y Romano, 2019), como construcción colectiva. La integración no se logra necesariamente con la cercanía con el otro, sino con la interacción, el contacto, el conocimiento, la cotidianeidad.

Opuesta al encuentro, está la segregación, que indica una desigual disposición o distribución de grupos sociales con diferentes identidades económicas, culturales, raciales, etc., en un determinado territorio; da cuenta de lógicas de separación entre personas que viven en determinadas áreas de la ciudad y de quienes no se espera que salgan de allí (Cohen, Carrizosa y Gutman, 2016). La segregación es la "tendencia a la organización del espacio en zonas de fuerte homogeneidad social interna y de fuerte disparidad social entre ellas" (Castells, 2014, p. 204); una "disposición espacial aglomerada de un grupo social" (Sabatini, Cáceres y Cerda, 2001, p. 30) que puede ser tanto del orden de lo material como de lo simbólico; es decir, de la percepción que los agentes sociales construyen de sus territorios urbanos, de su participación, de sus derechos a construirlos, etcétera.

Pensar en la integración social y la segregación es vincularlas con el derecho a la ciudad, idea iniciada por Lefebvre y recuperada por Harvey: "derecho colectivo; más que el acceso individual a re- 
cursos en la ciudad, un derecho a cambiarse a sí mismo transformando la ciudad" (Ruiz Tagle, 2016, p. 48). El derecho de tener espacios públicos que permitan el encuentro, el intercambio con libertad y sin discriminación; el derecho a la vivienda, a los servicios urbanos, a la calidad ambiental, a la accesibilidad y a la movilidad, a la identidad del lugar, entre otros (Borja, 2014).

La idea de frontera es un instrumento heurístico que permite abordar cualquier fenómeno que involucre procesos de fragmentación y diferenciación, pero también de integración. Se coincide con Bartolomé (2006, p. 6) cuando define a la frontera como:

[...] un ámbito que separa pero que a la vez reúne, puesto que no habría fronteras sin nadie del otro lado, por lo que la frontera no sólo distingue [...], sino también ofrece una definición posible del "nosotros" que se contrasta con los de afuera de los límites. [...] Son los lugares propicios para la articulación social y el consiguiente desarrollo de nuevas configuraciones sociales.

Las fronteras están en constante cambio debido a las dinámicas que hacia su interior y con el exterior se dan entre los agentes sociales que participan y, por lo tanto, van obteniendo "nuevos contornos" (Trejo, s/f). Existen fronteras materiales y simbólicas, intra e interurbanas (Dalla Torre y Ghilardi, 2019), como las que se identifican en el espacio urbano estudiado. Fronteras materiales como paredes, muros, ingresos vallados y autopistas intraurbanas pueden observarse a diferentes escalas (del AMM, de los municipios -entre ellos, el de la Ciudad de Mendoza-, en las secciones en que esta ciudad se divide, en los barrios que la componen, etc.), al igual que las fronteras simbólicas, las cuales constituyen imágenes, formas discursivas, pensamientos y sentimientos; construcciones simbólicas, invisibles (no palpables) pero existentes, pues pueden invisibilizar al otro (Trejo, s/f).

Las políticas públicas ayudan a una determinada producción del espacio urbano y a determinadas pautas de apropiación del mismo (Hiernaux, 2007). Esto lleva a la conformación y/o a la eliminación de fronteras materiales y simbólicas que, a su vez, favorecen la integración urbana o, por el contrario, la reproducción de la segregación 
socioespacial de ciertos grupos, por lo que fragmentan cada vez más la ciudad como un todo.

\section{La construcción del Parque Lineal Norte: ¿una política de intervención urbana que permite la integración social?}

Este apartado indaga la política desarrollada en el Parque Lineal Norte de la Ciudad de Mendoza y su diálogo con la idea de integración social. La información construida proviene del análisis de documentos oficiales disponibles del municipio y de la ciudad, particularmente el Proyecto Parque Lineal Norte, dependiente del Departamento de Arquitectura, y de registros fotográficos disponibles. Se indagó el proceso de diseño y aplicación de este ejemplo de intervención urbana en el marco de las políticas territoriales desarrolladas por el gobierno de la Ciudad de Mendoza, en vinculación con las otras escalas de gobierno provincial y nacional.

Asimismo, se recuperaron testimonios de vecinos/as en el parque y se realizaron observaciones en terreno registradas mediante fotografías. Este trabajo de campo, realizado en dos etapas - una primera de aproximación hacia fines del 2018, y otra segunda en el mes de noviembre del mismo año-, supuso la construcción de categorías de análisis que permitieron centrar la búsqueda fundamentalmente en el uso y apropiación del parque por parte de vecinos/as y ciudadanía en general, y en su mirada respecto de las transformaciones materiales y simbólicas evidenciadas en el lugar.

Hacia el año 2014 el Municipio de Capital comenzó la obra de reutilización de los terrenos del ferrocarril en desuso luego de la privatización del servicio en los años noventa. Este proyecto significó la construcción del parque objeto de estudio y la recuperación y ampliación del espacio público de una parte del área noroeste del departamento.

El proyecto fue anterior a políticas urbanas centrales como el Plan de Renovación Urbana 2016-2021, anteriormente mencionado, que busca la renovación de los espacios públicos de la Ciudad de Mendoza, entre otras metas, y el Plan Municipal de Ordenamiento Territorial recientemente aprobado. No obstante, esta iniciativa ya 
mostraba interés por embellecer la urbe y por la ampliación y recuperación de terrenos en desuso.

El proyecto realizado contiene cuestiones arquitectónicas y paisajísticas de mejora respecto a la conectividad en el interior del departamento. De hecho, no hay ninguna referencia al logro de objetivos sociales ni a la recuperación del espacio público por medio de la renovación urbana que propició el Parque Lineal Norte.

En este sentido, se considera que su construcción ha significado una reconfiguración de toda un área de la Cuarta Sección del municipio que estaba en desuso, abandonada y olvidada, además de que era evitada por los transeúntes debido a su inaccesibilidad, falta de iluminación y de pasos seguros y, por lo tanto, era considerada peligrosa. Antes de la inauguración del Parque Lineal Norte sólo se encontraba la torre de Casa Magna, cuyo ingreso por calle 25 de Mayo, paralela al este a calle Perú, eludía a sus residentes recorrer la zona. Así, la única vereda concurrida por los/as vecinos/as era la vereda oeste, que sí contaba con una serie de negocios, además de algunos edificios y viviendas individuales. Esta situación se la puede vincular con la idea de Jane Jacobs (1973) de que la seguridad en el espacio público se garantiza cuando sus veredas son más frecuentadas. Es decir, la presencia del otro invita a recorrer o utilizar esos espacios y no otros.

En estas áreas de la ciudad el Estado municipal ha intervenido para prescindir de aquellos lugares que rompen la trama urbana: descampados, playas de estacionamiento que constituyen una fuente de plusvalía urbana por excelencia y otras áreas privatizadas, cerradas e hipercontroladas o segurizadas. También ha favorecido la iluminación y mejorado las veredas, antes intransitables, que no permitían una movilidad urbana fluida. Actualmente el parque es fácil de transitar; todos los cruces de calles han sido demarcados claramente para el uso prioritario del peatón y conectan el área al este y oeste de la ciudad. Los/as informantes manifiestan notorios cambios con relación al área anterior. Al respecto, una de las entrevistadas (vecina, 67 años) afirma:

El paseo nos brinda la oportunidad de llegar caminando al Parque Central. Es un camino seguro y hay gente todo el día [...] Antes las veredas eran estrechas, ubicadas entre un paredón y la avenida Perú. 
El parque ha revitalizado la zona y ha permitido generar un corredor mucho más fluido y seguro sur-norte fundamentalmente, $\mathrm{y}$ oeste-este, además de incentivar la ocupación y apropiación del territorio por parte de los/as vecinos/as, quienes confluyen desde diversos puntos aledaños. Incluso, existe actualmente una idea de continuidad con el Parque Central que permite una vía de acceso extensa hasta el municipio de Las Heras, donde nuevamente se corta la interacción. Esto lleva, en parte, a verificar el cambio de una frontera que separaba o dividía a otra, cuya característica es la relación o conjunción de áreas, permitiendo la integración urbana en contraposición a la segregación.

El uso actual que la comunidad le da al parque da cuenta del espacio de encuentro que éste supone. Y como tal, se espera que genere convivencia, respeto e integración. Un informante (varón, 20 años, habita a siete cuadras del parque, en la Sexta Sección de la Ciudad de Mendoza) dice:

Practico calistenia en el parque. Es el único lugar de la capital que tiene un circuito completo. Venir acá todos los días me permitió conocer a otros chicos y chicas que les gusta esta forma de ejercicios físicos, y se convirtió en nuestro punto de encuentro.

Se entiende que estas prácticas estatales en un sentido podrían contradecir a la visión mercantilista de la ciudad en la que el espacio público queda a expensas de los desarrolladores inmobiliarios y en la que el Estado ve -por omisión o activa presencia- a las áreas urbanas como mercancía o valor de cambio en el que el derecho a la ciudad no es respetado. En este mismo sentido, según el PMOT de la Ciudad de Mendoza, el objetivo central buscado desde la intervención del Estado es:

Avanzar hacia un territorio departamental equilibrado, continuo y diverso, mediante la planificación de un desarrollo urbanístico socialmente equitativo y ambientalmente amigable [...] con el fin de garantizar el bien común [Municipalidad de la Ciudad de Mendoza, 2019, p. 3].

Otro fragmento del PMOT afirma: 
[...] un modelo de ciudad donde el bienestar colectivo se logre mediante la existencia de espacios limpios, ambientes saludables [...], ciudadanos conscientes de su entorno en una ciudad inteligente, moderna y conectada [Municipalidad de la Ciudad de Mendoza, 2019, p. 5].

El predio incluye áreas para el desarrollo de distintas actividades. Hay una ciclovía, y en las esquinas se han realizado obras de infraestructura que permiten dar prioridad total a los ciclistas a la hora de atravesar las arterias que cortan de este a oeste el parque. Además, cuenta con una pista para caminar, un gimnasio a cielo abierto, una zona de juegos infantiles, un sector para practicar calistenia, y un predio sembrado e iluminado en toda su extensión para el disfrute del césped. Esto lo vuelve un lugar concurrido todo el año por los/as vecinos/as de la zona, así como de otros lugares más alejados del mismo municipio y de fuera, que no cuentan con espacios verdes cercanos (Fotografías 2, 3, 4).

\section{Fotografía 2}

Extremo sur del Parque Lineal Norte, estatua de Nicolino Locche, Ciudad de Mendoza, Argentina

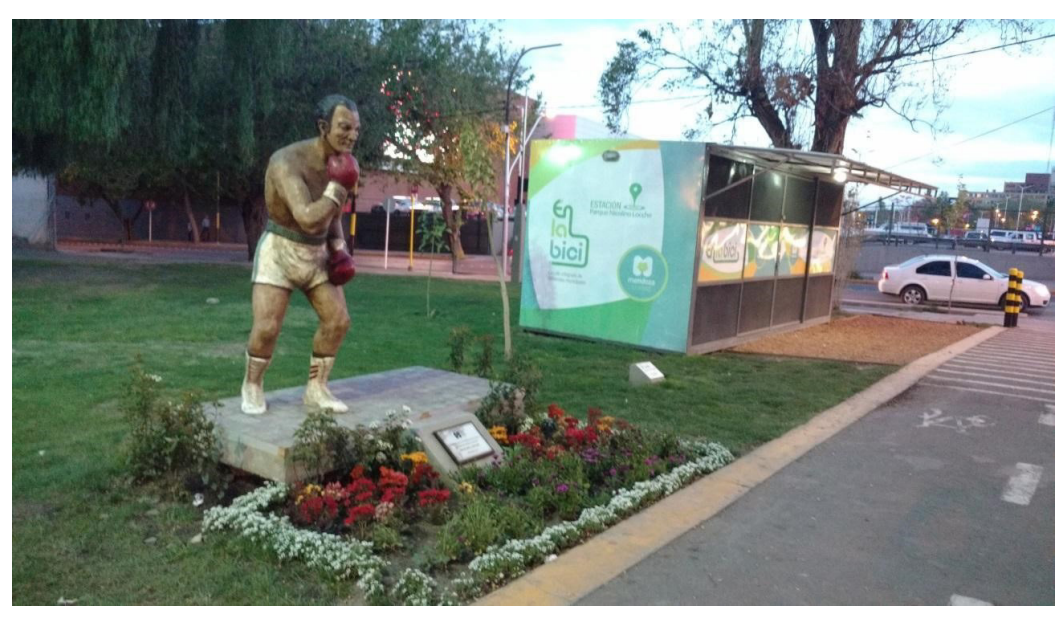

Fuente: Fotografía de los autores. 


\section{Fotografía 3}

Parque Lineal Norte, Ciudad de Mendoza, Argentina

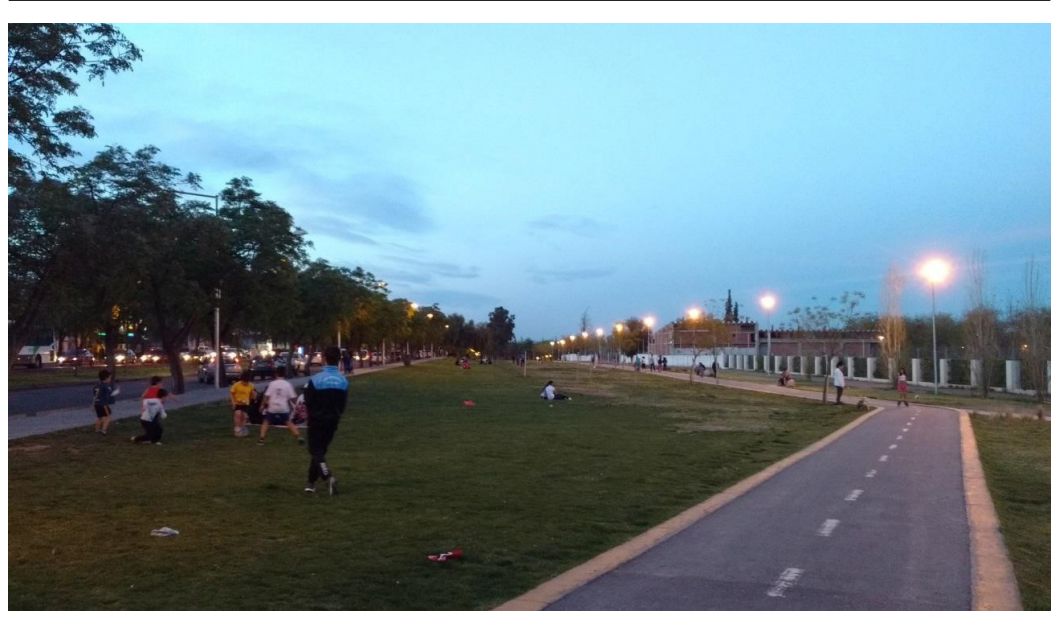

Fuente: Fotografía de los autores.

Además, se ha revalorizado el papel de las acequias (presente en el imaginario colectivo de los mendocinos). A lo largo del paseo se ha construido un pequeño canal (que suele traer agua, según el relato de vecinos/as) para hacer referencia a este patrimonio ambiental y urbano de Mendoza (véase la Fotografía 5), que tiene su origen prehispánico en el imperio inca y en la cultura huarpe, y que desde fines del siglo XIX tiene por función el riego de la arboleda urbana de Mendoza (Ponte, 2016).

Sin embargo, más allá de que la obra ha logrado relacionar mucho más al espacio e integrar al área a sus residentes, se identifican situaciones que aún remiten a la idea de separación. El proyecto no enuncia la importancia del Parque Lineal Norte para la vinculación de la ciudad con el departamento colindante de Las Heras, el cual presenta características distintas a la urbe, siendo uno de los municipios más pobres del AMM, en contraposición al de la ciudad, que es el más rico. En este sentido, mantiene las fronteras interdepartamentales. 


\section{Fotografía 4}

Parque Lineal Norte, ciclovía

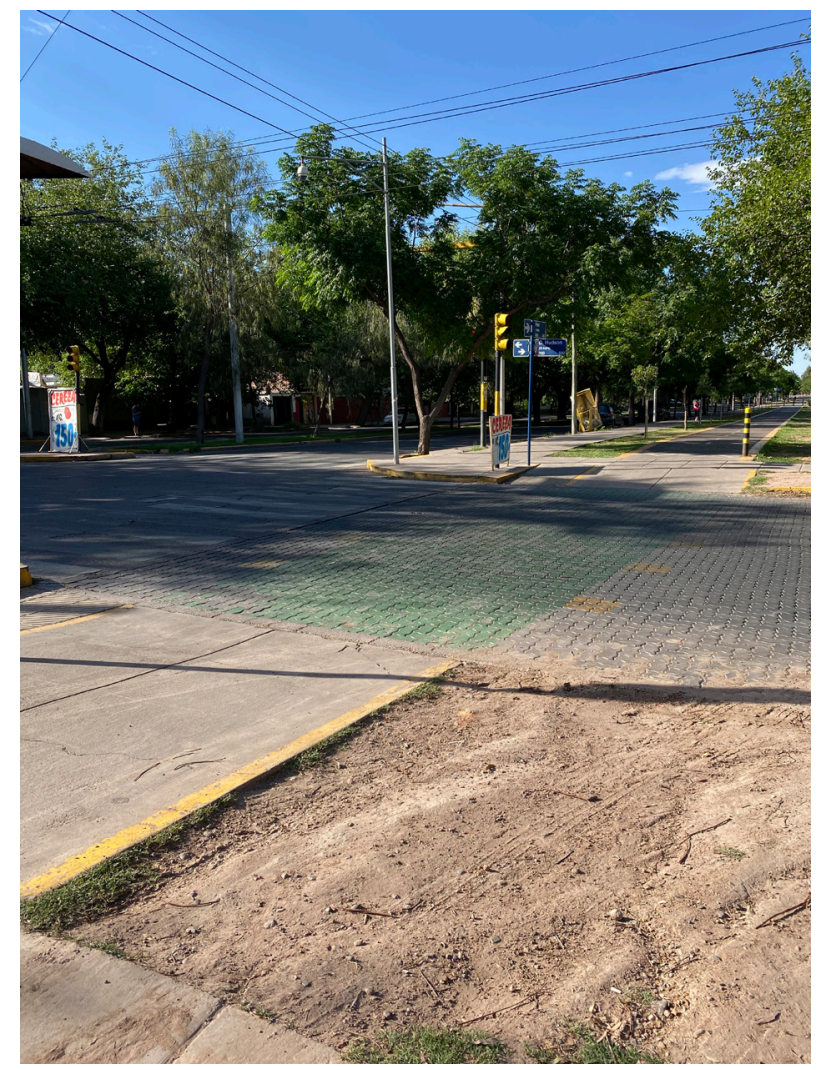

Fuente: Fotografía de los autores.

También se evidencia la idea recurrente de que el Parque Lineal Norte pertenece a la Ciudad de Mendoza; de que es una obra exclusiva de este municipio. Esta representación es incentivada desde el mismo gobierno y sus campañas de comunicación que, por un lado, buscan integrar socialmente desde lo discursivo, pero por otro, mantener las diferencias entre residentes de la Ciudad y el resto de la ciudadanía del AMM. En consecuencia, se entiende que desde el municipio no se planifica a escala metropolitana ni hay una idea de 
relación de la Ciudad con el AMM, menos aún con el municipio de Las Heras, con el que limita el área estudiada.

\section{Fotografía 5}

Parque Lineal Norte, acequias

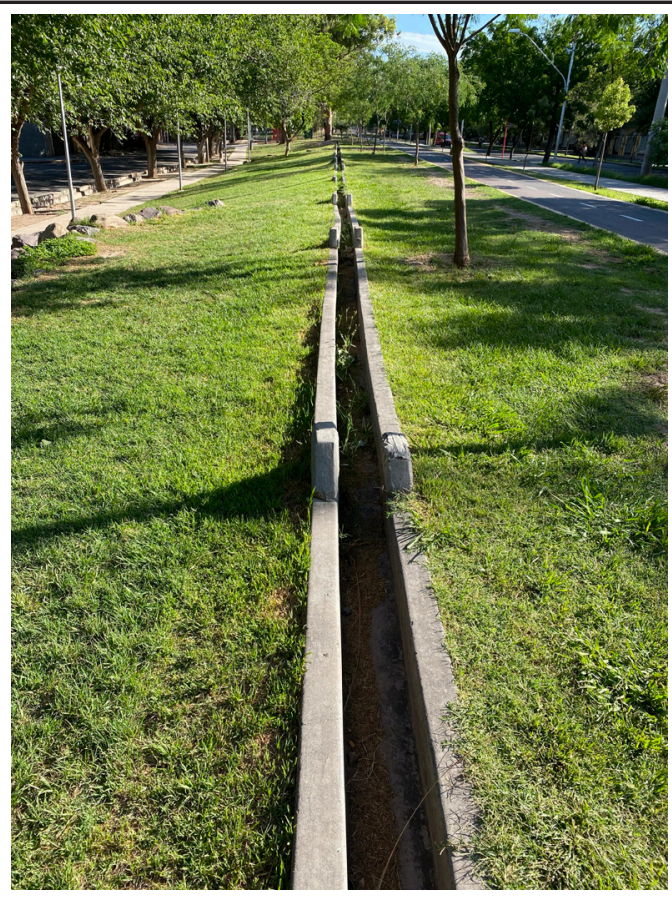

Fuente: Fotografía de los autores.

Otro ejemplo de falta de integración es la calle Perú. Los insuficientes cruces peatonales sobre esta arteria constituyen obstáculos a la movilidad y a la integración urbana de oeste a este. Particularmente, la rotonda ubicada entre las calles Perú y Pellegrini es otro elemento que dificulta el acceso dado el obstáculo que significa atravesarla con seguridad. Además, aún perdura un muro de grandes proporciones (tres metros de alto más cables de tensión) entre las calles Damián Hudson y Videla Correa, que corta la posibilidad de circulación. Asimismo, el área de juegos infantiles ha sido totalmente cer- 
cada con una tela romboidal, permitiendo el acceso a los niños en determinados horarios y por una sola puerta con candado, lo que significa una apropiación limitada de estos espacios, que son cercados con el objetivo manifiesto de cuidarlos del vandalismo, siendo que no se desarrolla desde el municipio ninguna campaña de cuidado de los espacios públicos ni de concientización acerca de su importancia y del rol central que tiene la comunidad en ello.

\section{Fotografía 6}

Parque Lineal Norte, área cerrada de juegos infantiles

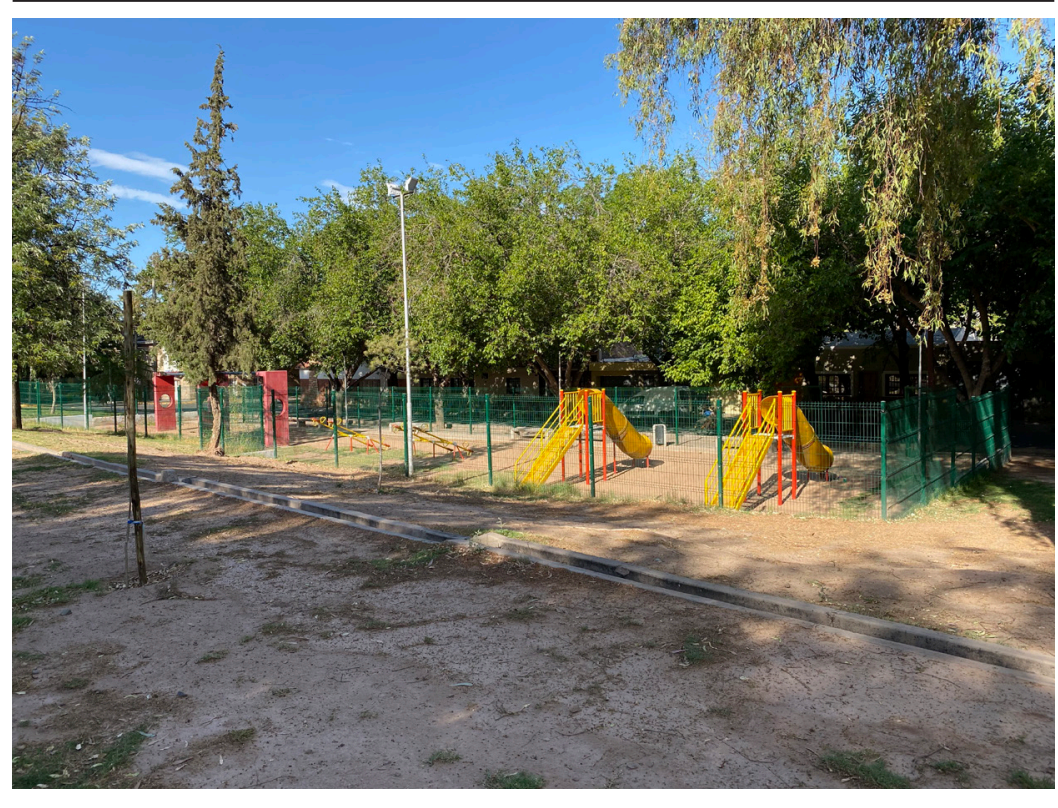

Fuente: Fotografía propia tomada durante el trabajo de campo.

Los espacios se cierran en el marco de prácticas estatales que supuestamente tienden a la apertura y recuperación de los espacios públicos sin una política sostenida que ayude a su apropiación y preservación colectiva. Se requieren entonces decisiones adicionales por parte del municipio, agente que debe asegurar el derecho al espacio público y así a la ciudad. 
A través de la lectura del PMOT (Municipalidad de la Ciudad de Mendoza, 2019) y del Proyecto de Obra del Parque Lineal Norte (Municipalidad de la Ciudad de Mendoza, 2014), se desprende que este proyecto de renovación y/o creación de espacios públicos urbanos tiene en cuenta un embellecimiento y puesta en valor del sector donde se localiza, sin incluir los beneficios que puede generar en pos de la integración social mediante la consolidación del espacio urbano. Las reformas logradas no fueron buscadas explícitamente por el municipio, ni fueron tenidas en cuenta desde el diseño y menos desde la implementación de la renovación y construcción del parque estudiado.

El hecho de no haber incorporado esta idea y haber obtenido buenos resultados, permite deducir y afirmar que los mismos podrían incluso ser mayores si se incluyera este punto de vista a la hora de proyectar las políticas vinculadas a los territorios urbanos. Es importante resaltar este punto dado que las consecuencias podrían haber sido otras. Como dice Borja (2014), no toda urbanización es sinónimo de crecimiento de la ciudad en la que sucede y menos aún de mejora para sus habitantes.

Se puede afirmar entonces que no se identificó a la obra como necesaria para la recuperación del espacio público, la interacción social y el intento de revertir los procesos de segregación urbana evidenciados. Se considera que los logros alcanzados se vinculan más con una cuestión espontánea que de planificación urbana.

\section{Algunas reflexiones finales}

El AMM puede ser concebida como una ciudad intermedia fragmentada que segrega a amplios sectores de sus habitantes, así como permite una marcada autosegregación de sus elites. Sin embargo, si se hace un análisis más acotado y limitado a situaciones concretas en espacios urbanos puntuales, se puede observar que, aunque desde la planificación urbana y las operaciones del Estado y del sector privado se privilegia un modelo de ciudad en fragmentos, en la cotidianeidad hay espacios de frontera en los que se dan relaciones entre diferentes áreas y dinámicas que es imprescindible rescatar desde lo 
discursivo, y fortalecer y fomentar desde la práctica. En estas áreas reside la posibilidad de transformar las ciudades neoliberales en ciudades vividas porque son lugares de encuentro que, por lo tanto, deben ser rescatados, valorizados e impulsados para la coincidencia y la construcción colectiva.

En este trabajo se ha analizado uno de estos casos, el del Parque Lineal Norte, ubicado en la Cuarta Sección Oeste de la Ciudad de Mendoza, que constituye un ejemplo de reconversión de un espacio de frontera que separaba, a otro que relaciona y permite la integración social.

Se considera que el mismo ha favorecido la construcción de un espacio no securizado desde lo formal, en el que la ciudadanía puede encontrarse y convivir, distinto a otras intervenciones realizadas en las que se busca privilegiar a algún grupo social sobre otro. No obstante, se entiende que, luego de la recuperación de los terrenos en desuso y de su puesta en valor, es necesario poner en práctica acciones de todo tipo que tiendan no solamente a la asistencia, ocupación y uso individual de estos territorios, sino a su apropiación y construcción colectiva. Entre estas prácticas deseables se encuentran las de cuidado y manutención del espacio como parte de la administración pública; también la enseñanza y el fomento de su conservación colectiva.

La cercanía que permite en este caso un área verde como el Parque Lineal Norte no implica necesariamente un proceso de construcción social conjunto, libre y democrático de los espacios urbanos. Se requiere tiempo, conocimiento mutuo, cotidianeidad, para lograr intercambios lo más respetuosos posibles de las diferencias sociales. Entonces, es importante incentivar el contacto a partir del impulso de lugares comunes, del espacio público, en detrimento de los lugares privados en los que el mercado inmobiliario impone las reglas (espacios cerrados que homogenizan).

Además, es central que las políticas urbanas sean pensadas y acordadas con la comunidad desde el momento inicial de su diseño. Se destaca así la relevancia de la participación de los agentes que cotidianamente construyen el espacio urbano en los procesos territoriales; de ahí la necesidad de que el Estado convoque a vecinos/as y a organizaciones de la sociedad civil, además de los sectores privados 
que representan al mercado inmobiliario. Existen varias experiencias exitosas en esta línea del trabajo urbanístico; entre las más interesantes se pueden destacar los avances respecto al espacio público, al diseño participativo y al activismo en la ciudad propuestos por el llamado urbanismo ciudadano o urbanismo táctico.

Asimismo, no es posible pensar prácticas estatales a escala municipal escindidas de otras, fundamentalmente provinciales y nacionales, que determinan procesos sociales, económicos y territoriales muchas veces contrarios.

Este planteamiento propone generar, por medio de intervenciones acotadas y de bajo costo, cambios a largo plazo en los espacios urbanos de la mano del trabajo mancomunado entre ciudadanos/as, organismos públicos e instituciones. Es importante, en este punto, la articulación en cuanto a fondos y diseño de planes y proyectos urbanos entre las distintas esferas estatales: supranacional, nacional, provincial y municipal, actualmente inexistente en la Ciudad de Mendoza. Así como también recuperar una escala más micro y una mirada más íntima para pensar las fronteras intraurbanas como posibles escenarios de integración y no sólo de separación y división, y de esta manera poder fomentar las construcciones colectivas y participativas del espacio público.

\section{Bibliografía}

Barreto, M. A. (2010). El concepto de hábitat digno como meta de una política integral de áreas urbanas deficitarias críticas, para la integración social desde los derechos humanos. Revista INVI, 25(69), 161-187. https://www.redalyc.org/pdf/258/25816625005.pdf

Bartolomé, M. A. (2006). Antropología de las fronteras en América Latina. AmeriQuests, 2(1), 1-17. http://vurj.vanderbilt.edu/ index.php/ameriquests/article/view/41

Benedetti, A. (2011). Territorio: concepto integrador de la geografía contemporánea. En P. Souto (coord.), Territorio, lugar, paisaje. Prácticas y conceptos básicos en geografia (pp. 11-82). Buenos Aires: Universidad de Buenos Aires. 
Borja, J. (2014). Revolución urbana y derechos ciudadanos: claves para interpretar las contradicciones de la ciudad actual. Buenos Aires: Café de las Ciudades.

Borja, J. y Muxí, Z. (2003). El espacio público, ciudad y ciudadanía. Barcelona: Electa.

Castells, M. (2014). La cuestión urbana. Ciudad de México: Siglo XXI.

Cohen, M., Carrizosa, M. y Gutman, M. (2016). Hábitat en deuda y activos a futuro: hacia una nueva práctica urbana inclusiva. En M. Cohen, M. Carrizosa y M. Gutman (eds.), Hábitat en deuda. Veinte años de políticas urbanas en América Latina (pp. 501517). Buenos Aires: Café de las Ciudades.

Consejo Nacional de Coordinación de Políticas Sociales. (2019). Agenda 2030, Objetivos de Desarrollo Sostenible. Buenos Aires: Presidencia de la Nación.

Construya Calidad (s/f). El emblema de calidad de Construya deja su sello grabado en Mendoza. Buenos Aires: Grupo Construya Calidad. https://www.grupoconstruya.com.ar/notas/Informes Detalles?CCTN=794\&CINF=72 (3 de abril de 2019).

Dalla Torre, J. y Ghilardi, M. (2019). Situaciones de segregación y fronteras simbólicas intraurbanas en el Área Metropolitana de Mendoza. En E. Salizzi y J. Barada (comps.). Fronteras en perspectiva, perspectivas sobre las fronteras (pp. 25-56). Buenos Aires: Universidad de Buenos Aires.

DEIE. (varios años). Mendoza en datos. Argentina: Gobierno de Mendoza, Dirección de Estadísticas e Investigaciones Económicas. http://www.deie.mendoza.gov.ar/\#!/mendoza-en-datos

Del Río, J. P., Vértiz, F. y Ursino, S. (2014). La acción pública en el espacio urbano. Debates y reflexiones en torno a la noción de política urbana. Estudios Sociales Contemporáneos, 11, 76-86. https:// bdigital.uncu.edu.ar/objetos_digitales/6826/07-delrio-esc11.pdf

Di Virgilio, M. y Rodríguez, M. C. (comps.) (2013). Producción social del hábitat. Abordajes conceptuales, prácticas de investigación y experiencias en las principales ciudades del Cono Sur. Buenos Aires: Café de las Ciudades.

Di Virgilio, M., Herzer, H., Merlinsky, G. y Rodríguez, M. C. (2011). La cuestión urbana interrogada. Transformaciones urbanas, 
ambientales y políticas públicas en Argentina. Buenos Aires: Café de las Ciudades.

Diario Noticias Cuyo. (s/f). Quedó inaugurado el paseo que brinda homenaje a Nicolino Locche. Redacción Noticias Cuyo. http:// www.noticiascuyo.com/shop/detallenot.asp?notid=13174 (12 de diciembre de 2018).

Galarza, B. y Corte, V. (2015). El espacio público tatuado: murales por reclamos ambientales. En A. Gravano, A. Silva y S. Boggi (eds.), Ciudades vividas. Sistemas e imaginarios de ciudades medias bonaerenses (pp. 321-343). Buenos Aires: Café de las Ciudades.

Ghilardi, M. y Dalla Torre, J. (2016). La segregación y el derecho a la ciudad en el Área Metropolitana de Mendoza, Argentina. Congreso Internacional Madrid. Contested Cities, 2(521), 1-12. http://contested-cities.net/wp-content/uploads/sites/8/2016/07/ WPCC-162521-GhilardiDalla-ApropriacionesUsosSuelo ViviendasUrbanasAgentesPr\%C3\%A1 cticasL\%C3\%B3gicas Intervinientes.pdf

Gobierno de Mendoza. (2009). Ley de Ordenamiento Territorial y Usos del Suelo núm. 8051. http://www.mendoza.gov.ar/wpcontent/uploads/sites/44/2017/01/Ley-8051.pdf

Gobierno de Mendoza. (2017). Plan Provincial de Ordenamiento Territorial de Mendoza. Ley núm. 8999. https://www.legisla turamendoza.gov.ar/wp-content/uploads/2017/12/4_8999_plan ordenamiento territorial.pdf

Gobierno de la Nación. (2016). Informe Nacional de la República Argentina. Conferencia de las Naciones Unidas sobre la Vivienda y el Desarrollo Urbano Sostenible (Hábitat III). Buenos Aires. https://www.argentina.gob.ar/sites/default/files/interior informe_nacional_republica_argentina_onu_0.pdf

Gudiño, M. E. (2010). Pasado, presente y futuro del ordenamiento territorial. Ley $\mathrm{N}^{0}$ 8051/09 de la provincia de Mendoza. Proyección, 8, 1-6. https://bdigital.uncuyo.edu.ar/app/navegador/? idobjeto $=11248$

Hiernaux, D. (2007). Los imaginarios urbanos: de la teoría y los aterrizajes en los estudios urbanos. Revista Latinoamericana de Estudios Urbano Regionales, Eure, 33(99), 17-30. https://scielo.conicyt.cl/ scielo.php?script $=$ sci_arttext\&pid=S0250-71612007000200003 
INDEC. (2010). Censo Nacional de Población, Hogares y Vivienda. Argentina: Instituto Nacional de Estadísticas y Censos.

Jacobs, J. (1973). Muerte y vida de las grandes ciudades. Madrid: Península.

Lentini, M. y Palero, D. (2008). Todos tienen derecho a una casa, pero cada uno en su lugar: alcances del derecho a la vivienda y a la ciudad en una sociedad excluyente. V Jornada Internacional de Vivienda Social, Universidad de Chile / Universidad de Valparaíso.

Lentini, M., Palero, D. y Montaña, E. (2010). La inequidad en el acceso al suelo urbano: los procesos de segregación residencial e informalidad urbana. XI Seminario Internacional RII: Desigualdades Territoriales, Mendoza, Argentina.

Marina-Berón, N., Padilla-Rodríguez, C. y Rapali, N. (2013). Nuevo marco normativo de ordenamiento territorial en Mendoza: su aplicación en el Área Metropolitana. Bitácora, 22(1), 97-108.

Ministerio de Planificación Federal, Inversión Pública y Servicios. (2008). Plan Estratégico Territorial. Buenos Aires: Gobierno de la Nación. http://www.infoleg.gob.ar/basehome/actos_gobierno/ actosdegobierno10-11-2008-1.htm

Ministerio de Planificación Federal, Inversión Pública y Servicios. (2011). Plan Estratégico Territorial (PET) Avance II: Argentina Urbana. Lineamientos estratégicos para una politica nacional de urbanización. Buenos Aires. https://www.mininterior.gov.ar/ planificacion/pdf/PETII-LibroI.pdf

Ministerio del Interior, Obras Públicas y Vivienda (2016). Informe Nacional de la República Argentina sobre Conferencia de las $\mathrm{Na-}$ ciones Unidas sobre la Vivienda y el Desarrollo Urbano Sostenible (Hábitat III). Evaluación del progreso y medidas orientadas a futuro. Argentina: Gobierno de la Nación. http://habitat3.org/ wp-content/uploads/Informe-Nacional-Republica-ArgentinaFINAL-spanish.pdf

Ponte, J. R. (2016). El sistema de acequias y arboleda urbana como patrimonio cultural. Un modelo exitoso que se debe preservar y conservar. Unidiversidad. Mendoza: Universidad Nacional de Cuyo. http://www.unidiversidad.com.ar/el-sistemade-acequias-y-arboleda-urbana-como-patrimonio-cultural 
Raffa, C. (2016). Plazas fundacionales: el espacio público mendocino entre la técnica y la política, 1910-1943. Guaymallén, Mendoza. http://bdigital.uncu.edu.ar/objetos_digitales/9256/ra ffa-plazasfundacionales.pdf

Raffa, C. (2017). Espacio público, del uso limitado al uso popular. Unidiversidad. Mendoza: Universidad Nacional de Cuyo. http:// www.unidiversidad.com.ar/espacio-publico-del-uso-limitadoal-uso-popular

Rizzo, P. (2005). El espacio público urbano, entre la disputa y la dominación. Boletín de Estudios Geográficos, 100, 9-30. https:// bdigital.uncu.edu.ar/objetos_digitales/5520/001rizzo-beg-100. pdf

Rizzo, P. (2010). El espacio público de la Ciudad de Mendoza (Argentina), espacio de disputa y expresión ciudadana. An International Journal for Critical Geographies, ACME, 9(2), 164-190. https://www.acme-journal.org/index.php/acme/article/view/865

Roitman, S. (2000). Transformaciones urbanas en los '90: los barrios cerrados del Área Metropolitana de Mendoza. IV Jornadas de Sociología. Buenos Aires: Universidad Nacional de Buenos Aires.

Roitman, S. (2003). Barrios cerrados y segregación social urbana. Revista Electrónica de Geografia y Ciencias Sociales, Scripta Nova, 7(146). http://www.ub.edu/geocrit/sn/sn-146(118).htm

Ruiz-Tagle, J. (2016). La segregación y la integración en la sociología urbana: revisión de enfoques y aproximaciones críticas para las políticas públicas. Revista INVI, 31(87), 9-57. http://www. revistainvi.uchile.cl/index.php/INVI/article/view/1070

Ruiz-Tagle, J. y Romano, S. (2019). Mezcla social e integración urbana: aproximaciones teóricas y discusión del caso. Revista INVI, 34(95), 45-69. http://revistainvi.uchile.cl/index.php/INVI/ article/view/1442

Sabatini, F., Cáceres, G. y Cerda, J. (2001). Segregación residencial en las principales ciudades chilenas: tendencias de las tres últimas décadas y posibles cursos de acción. Revista Latinoamericana de Estudios Urbano Regionales, Eure, 28(82), 2142. https://scielo.conicyt.cl/scielo.php?script=sci_arttext\&pid= S0250-71612001008200002 
Salomone, M. (2011). La "okupación" como forma de recuperación del espacio público. La experiencia del colectivo Casa Amérika en Mendoza (2006-2008). Revista de Temas Sociales, Kairos, 27, 1-24. https://dialnet.unirioja.es/servlet/articulo?codigo= 3702606

Salomone, M. (2012). Territorio y política: disputa social y memoria histórica. La defensa de la estación del ferrocarril como espacio público, Mendoza 2006-2008. Revista Cuadernos de la Facultad de Humanidades y Ciencias Sociales, Universidad Nacional de Jujuy, 41, 145-175. http://revista.fhycs.unju.edu.ar/revista cuadernos/index.php/cuadernos/article/view/31/68

Secretaría de Ambiente y Ordenamiento Territorial. (2017). Plan Provincial de Ordenamiento Territorial (POT). Argentina: Gobierno de Mendoza.

Secretaría de Planificación, Infraestructura y Ambiente. (2019). Informe final. Audiencia pública. Municipalidad de la Ciudad de Mendoza. https://ciudaddemendoza.gob.ar/wp-content/ uploads/2019/05/Informe-final-audiencia.pdf

Trejo, Z. (s/f). Indigenas, fronteras simbólicas e imaginarios sociales. El Colegio de Sonora. http://www.academia.edu/4404941/ Ind\%C3\%ADgenas_frontera_imaginarios_sociales (20 de agosto de 2019).

\section{Acerca de los autores}

Julieta Dalla Torre es licenciada y profesora en Sociología por la Universidad Nacional de Cuyo (Mendoza, Argentina); así como maestra en Ciencia Política y Sociología, y doctora en Ciencias Sociales, ambos por la Facultad Latinoamericana de Ciencias Sociales (Flacso), Argentina. Es investigadora asistente del Consejo Nacional de Investigaciones Científicas y Técnicas (Conicet), con lugar de trabajo en el Instituto Multidisciplinario de Estudios Sociales Contemporáneos (IMESC) del Instituto de Estudios Históricos, Económicos, Sociales e Internacionales (IDEHESI), Conicet, Mendoza, Argentina. Es profesora titular en la Facultad de Ciencias Políticas y Sociales de la Universidad Nacional de Cuyo. Sus principales lí- 
neas de interés son: estudios urbanos, territorios y fronteras urbanas, fragmentación espacial y segregación social. ORCID: https://orcid. org/0000-0002-1355-0445

Entre sus publicaciones se encuentran:

Dalla Torre, J. y Ghilardi, M. (2019). Situaciones de segregación y fronteras simbólicas intraurbanas en el Área Metropolitana de Mendoza. En E. Salizzi y J. Barada (comps.), Fronteras en perspectiva, perspectivas sobre las fronteras (pp. 25-56). Buenos Aires: Universidad de Buenos Aires.

Dalla Torre, J., Sales, R., Esteves, M. y Ghilardi, M. (2019). Los territorios de interfase urbano-rural en tierras secas. Reflexiones sobre su tratamiento en las políticas de ordenamiento territorial de Mendoza. Revista QUID 16, 11, 137-150. https://publicaciones. sociales.uba.ar/index.php/quid16/article/view/3600/pdf

Esteves, M., Sales, R., Dalla Torre, J. y Ghilardi, M. (2018). Planificación del hábitat rural en territorios segregados no irrigados de Mendoza, Argentina: entre la acción local y la estatal. Estudios del Hábitat, 16(2), 1-16. https://revistas.unlp.edu.ar/Habitat/ article/view/5606/5490

Matías Ghilardi es geógrafo por la Universidad Nacional de Cuyo (Mendoza, Argentina). Es profesional adjunto del Consejo Nacional de Investigaciones Científicas y Técnicas (Conicet), con sede en el Instituto Multidisciplinario de Estudios Sociales Contemporáneos, (IMESC) del Instituto de Estudios Históricos, Económicos, Sociales e Internacionales (IDEHESI), Conicet, Mendoza, Argentina. Es profesor titular en el Departamento de Geografía de la Facultad de Filosofía y Letras de la Universidad Nacional de Cuyo. Sus principales líneas de interés son: estudios urbanos, fundamentalmente temáticas referidas a procesos de fragmentación socioterritorial. ORCID: https://orcid.org/0000-0003-0390-3961

Entre sus publicaciones se encuentran:

Ghilardi, M. y Benedetti, A. (2019). Fronteras en la vida cotidiana del Área Metropolitana de Mendoza (Argentina). En M. Valero Martínez, E. Superti y J. L. Rebelo Porto (coords.), Las ciudades entre miradas diversas (pp. 50-78). Brasil: Universidad Federal de Amapá. 
Ghilardi, M. y Dalla Torre, J. (2019). Situaciones de segregación y fronteras simbólicas intraurbanas en el Área Metropolitana de Mendoza. En Salizzi, E. y J. Barada (comps.), Fronteras en perspectiva, perspectivas sobre las fronteras (pp. 25-56). Buenos Aires: Universidad de Buenos Aires.

Salizzi, E., Rascovan, A., Porcaro, T., Tommei, C. y Ghilardi, M. (2019). Fronteras argentinas: aportes para una sistematización de su campo de estudio. Revista Internacional de Fronteras, Territorios y Regiones. Frontera Norte, 31, 1-23. http://www.scielo. org.mx/pdf/fn/v31/0187-7372-fn-v31-e2048.pdf

Recepción: 29 de agosto de 2019. Aceptación: 7 de febrero de 2020. 
